\title{
PLANTAS INVASORAS DA CULTURA \\ DE ARROZ (Oryza sativa L.) \\ NO ESTADO DE SÃO PAULO \\ 2 - Monocatiledôneas
}

\section{RESUMO}

Foi realizado um levantamento das plantas invasoras na cultura do arroz, concentrado nas regiões com maior área cultivada no Estado de São Paulo.

Cada uma das espé cies levantadas foi es tudada em seu ciclo, porte, fenologia e modo ou modos de reprodução. O hábito de crescimento herbáceo, o ciclo anual, o florescimento e frutificação nos meses mais quentes do ano e a reprodução através de sementes foram preponderantes.

Cada gênero representado por mais de uma espécie mereceu a confecção de chave analítica auxiliar objetivando ofe recer algum subsídio para a identificação da espécie em sua primeira fase de desenvolvimento.

Foram levantadas as sinonímias científica e vulgar e, sempre que possivel, localizada a etimologia do termo que se prestou à nomenclatura genérica e específica.

De cada espécie é fornecida uma diagnose da plântula além da ilustração planificada, tornando, portanto, mais fácil o reconhecimento da mesma.

Das seis familias monocotiledôneas encon tradas, num total de 26 espécies identificadas, quantitativamente mereceram destaque as seguintes: Gramineae, Cyperaceae e Commelinaceae.

Palavras-chave: levantamento, planta invasora, arroz, biologia.
C. ARANHA* \& R.M. PIO**

* Pesquisador Científico, bolsista do CNPq.

** Biogolista, contratada pelo Convênio IAC. -EMBRAPA.

Seçăo de Botânica-Econômica, Instituto Agronômico, Caixa Postal 28, 13.100 Campinas, SP.

\section{SUMMARY}

WEEDS OCCURING IN RICE CROPS (Oryza sativa L.) IN THE STATE OF SAO PAULO.

\section{MONOCOTYLEDONS.}

A survey of weeds growing in rice crops in the State of São Paulo was conducted.

The life cycle, size, phenology and mode of reproduction of each of the collected species were studied. The herbaceous growth, annual life cycle, blooming and fructification during the warmest months of the year and dissemination by seeds were mainly predominant for the studied species.

From the six monocotyledoneous families observed with a total of 26 identified species, three were quantitatively more important: Gramineae, Cyperaceae and Commelinaceae.

A taxonomical key was written for those genera with more than one species in an attempt to help identification in the first growth stage.

All the scientific and common names and when possible, the etimology of the genera or species were included.

In order to facilitate the keying and classifi cation of seedlings from each of the studi ed species, a description and a drawing are provided.

Keywords: Survey, weeds, rice, biology. 


\section{INTRODUÇÃO}

Em sequência ao levantamento botânico das plantas invasoras da cultura arrozeira do Estado de São Paulo, apresentam-se, nesta segunda parte, os resultados obtidos com a classe das monocotiledôneas.

Apesar de numericamente a quantidade de espécies ser menor que as dicotiledôneas, sua ocorrência na cultura é mais prejudicial em função do ciclo e do sistema radicular, semelhantes ao da planta cultivada. Outrossim, a grande dificuldade em se caracterizar cada uma dessas espécies em estádio de plântula, quase que obriga ao combate generalizado dessas espécies $(17,18,20,21)$.

Nesse levantamento consideraram-se importantes as monocotiledôneas detectadas através dos levantamentos e das visitas aos ensaios de herbicidas nas áreas explícitas na metodologia da primeira parte desse trabalho $(2,3,4,10$, 11).

\section{MATERIAIS E MÉTODOS}

Para o levantamento botânico das plantas invasoras procedeu-se da seguinte forma: foram visitadas e observadas diversas culturas de arroz em diferentes regiões do Estado de São Paulo como São José do Rio Preto, Ribeirão Preto, Campinas, Sorocaba e Marília, as quais são representativas das áreas plantadas. Esse levantamento botânico foi efetuado em três épocas do ano e por quatro anos consecutivos, de forma a se obter o maior número de espécies botânicas, evitandose, também, a inobservância de outras que pudessem estar em entreciclos $(1,15$, 16).

Os materiais oriundos dos levantamentos foram, depois de colhidos, devidamente prensados, secados, identificados, fichados, preparados e incorporados ao Herbário da Seção de Botânica Econômica do IAC.

A identificação do material botânico procedeu-se no laboratório de Taxonomia e Sistemática Vegetais da referida
Seção, com o auxílio de um microscópio estereoscópico Bausch \& Lomb (40x de aumento) com iluminação direta e regulador de voltagem da mesma marca, e bi bliografia especializada $(5,6,7,8,9,12$, 13, 14).

De cada espécie encontrada foram colhidas sementes e semeadas em casa-devegetação para obtenção das plântulas que se prestaram à confecção dos desenhos planificados, e realização das respectivas diagnoses. As plântulas excedentes foram mantidas e tratadas para que desenvolvessem todo seu ciclo, prestandose assim, para as observações de florescimento, frutificação e modo de reprodução.

\section{RESULTADOS E DISCUSSÃO}

Das espécies estudadas são fornecidos a etimologia (19), sinonímia científica e vulgar (12), ciclo, hábito de crescimento, fenologia, modo ou modos de reprodução, organografia e ilustrações das plântulas quando possivel (6).

Nos gêneros botânicos representados por mais de uma espécie foram confeccionadas chaves analiticas auxiliares possibilitando aos não botânicos maior facilidade para a identificação das mesmas.

\section{Familia Alismataceae}

Gênero:

Sagittaria Rupp. ex L. Syst. ed. I, 1735.

Etimologia:

em alusão à constância de suas folhas em forma de seta.

Sagittaria montevidensis Cham. et Schlecht. in Linnaeae 156, 1753.

Nome vulgar: aguapé.

Etimologia: por ter sido localizada na cidade de Montevideo.

Ciclo: perene.

Porte: herbáceo.

Fenologia: floresce nos meses de fevereiro-abril e fru- 


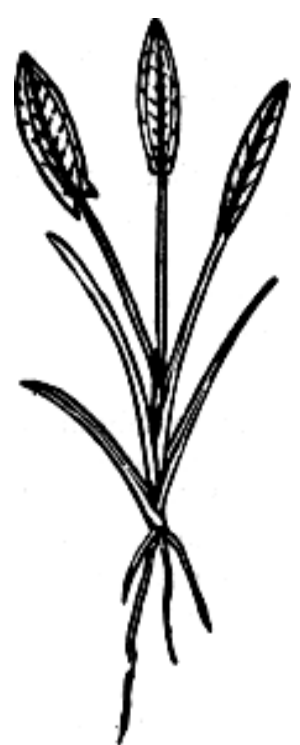

Fig. 1 - Saggitaria montevidensis (L.) Cham. et Schlecht

tifica nos meses subsequentes ao da florada. Reprodução:

sementes e através de rizomas. Plântula:

plúmula brancacenta, glabra, de boca oblíqua e longitudinalmente estriada. Primeiras folhas definitivas (3 ou 4) lineares, verdes, glabras em ambas as faces e com apenas a nervura central perceptivel. Folhas definitivas posteriores longamente pecioladas, membranáceas, verdes e glabras em ambas as faces, inicialmente lanceoladas, passando, gradualmente, a sagitadas, com três nervuras proeminentes na face superior e de bordos integros. (Fig. 1).

\section{Familia Commelinaceae}

Gênero:

Commelina Plum. ex L. Syst. ed. I, 1735.

Etimologia:

Em homenagem ao botânico holandês, Gaspar Commelin, 1667-1753.

Commelina agraria Kunth. Enum. 4:38, 1806.

Sin. Cient.:

Commelina cayennensis Rich. Act. Soc. Hist. Nat. Paris, 1: 106, 1810.

Commelina communis Vell. Flor. Flum. 1. t.59, 1827.

Commelina prostrata H.B.K. Nov. Gen. 1: 259, 1815.
Nome vulgar:

trapoeraba.

Etimologia:

em alusão a sua ocorrência em campo abertos.

Ciclo:

anual.

Porte:

herbáceo, prostrada tendo muitas ramificações com as porções terminais eretas.

Fenologia:

floresce nos meses de novembro-janeiro e frutifica nos meses subsequentes. Reprodução: sementes, pode se manter vegetativamente através de enraizamento dos nós em contato com o solo.

Plântula:

plúmula brancacenta, glabra, longitudinalmente estriada e de ápice levemente obtuso. Primeira folha definitiva elitico-lanceolada, semicarnosa, totalmente glabra, de bordos íntegros, verde-escura na face superior e cla ra na inferior. Bainha invaginante verde brancacenta, longitudinalmente estriada, de boca ligeiramente obliqua e com alguma pilosidade simples e alvo translúcida. (Fig. 2).

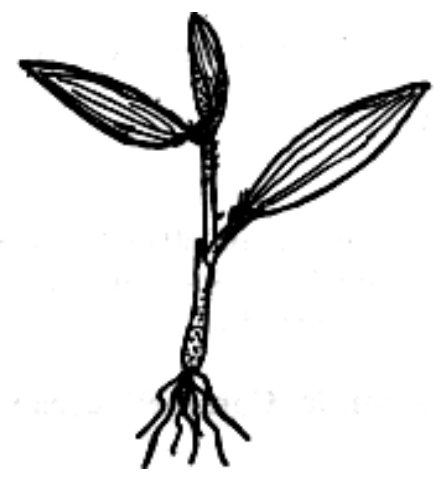

Fig. $2-$ Commelina agraria Kunth.

\section{Familia Commelinaceae}

Commelina nudifloralL. Sp. Pl. 4, 1753.

Sin. Cient.

Commelina longicaulis Jacq. Ic. Pl. Rar. 2. t. 294, 1786-93.

Nome vulgar: trapoeraba.

Etimologia: por apresentar o pedicelo da flor desenvol- 


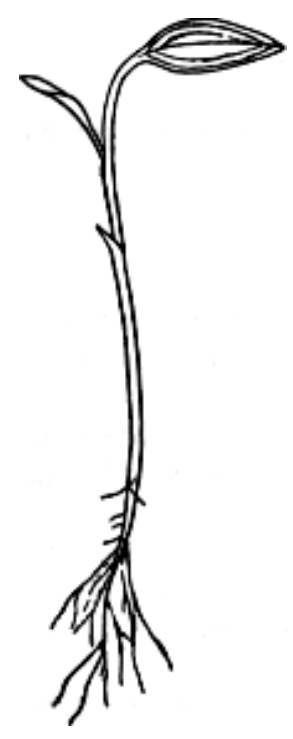

Fig. 3 - Commelina nudifloral $L$.

vido fazendo com que ela após a antese esteja acima das brácteas espatáceas.

Ciclo: perene.

Porte:

herbáceo, planta semi-prostrada.

Fenologia:

floresce e frutifica nos meses de outubrofevereiro.

Reprodução: estolões.

Plântula:

Não há formação de plântula por não ocorrer a produção de sementes nas condições do Estado. (Fig. 3).

\section{Família Commelinaceae}

Gênero:

Tradescantia Rupp. ex L. Syst. ed. I, 1735.

Etimologia: não encontrada.

Tradescantia elongata G.F.W. Mey. Prim. Fl. Esseq. 146, 1897.

Nome vulgar: trapoeraba.

Etimologia:

devido as ramificações do caule se alongarem após enraizamento nos nós.

Ciclo:

anual.
Porte:

herbáceo, prostrada, com as extremidades dos ramos eretos.

Fenologia:

floresce e frutifica abundantemente nos meses mais quentes do ano.

Reprodução:

sementes e vegetativamente por enraizamento caulinar.

Plântula:

plúmula tênue - membranácea, hialina, de ápice agudo e com densa pilosidade simples e translúcida. Primeiras folhas definitivas verdeclaras, espatulado-lanceoladas, agudas pelo ápice, membranáceas, glabras em ambas as faces, com os bordos esparsamente ciliados por curtos pelos simples e translúcidos, e bainha denso-pilosa, abraçando o caule róseo devido à pigmentação antociânica. (Figu. 4).

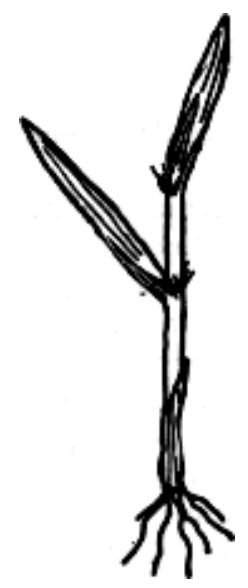

Fig. 4 - Tradescantia elongata G.F.W. Mey.

\section{Família Cyperaceae}

Gênero:

Bulbostylis Kunth. Enum. 2:205, 1837.

Etimologia:

devido aos talos simples originados de bulbo.

Bulbostylis cappillaris (L.) C.B. Clarke in Hook. f. Fl. Brit. Ind. 6:652, 1893.

Nome vulgar: alecrim-da-praia.

Etimologia:

por suas folhas muito filiformes formando 


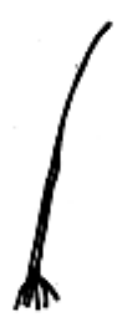

Fig. $5-$ Bulbostylis cappillaris (L.) C.B. Clarke

pequeninas touceiras, como se fossem fios de cabelos.

Ciclo:

anual.

Porte:

herbáceo.

Fenologia:

floresce e frutifica nos meses de janeiro.. maio.

Reprodução:

sementes.

\section{Família Cyperaceae}

Gênero:

Cyperus L. Syst. ed. I (1735).

Etimologia:

Provêm do nome grego do junco.

A chave de plântulas dessa família não foi confeccionada tendo em vista que os aspectos organográficos de seus representantes não permitiriam uma identificação correta das espécies tratadas.

\section{Família Commelinaceae}

Gênero:

Commelina Plum. ex L. Syst. ed. 1, 1735.

Etimologia:

Em homenagem ao botânico holandês, Gaspar Commelin, 1667-1753.

Chave para identificação das espécies:

1 - Primeiras folhas definitivas elitico-lanceoladas, verde-claras, glabras em ambas as faces

C. nudiflora.

- Primeiras folhas definitivas oblongolanceoladas, verde-escuras e com pilosidade simples e translúcida no pecíolo e nas nervuras da face inferior

C. agraria.

\section{Família Cyperaceae}

Cyperus acicularis (Schrad.) Steud. Syn. P1. Cyp. 45, 1855.

Nome vulgar: tiririca.

Etimologia:

do latim "acicula, ae" = alfinete, agulha.

Por suas folhas terem a forma de agulha. Ciclo: anual.

Porte:

herbáceo.

Fenologia:

floresce e frutifica nos meses de novembro a março.

Reprodução:

sementes e vegetativamente através de rizomas. (Fig. 6).

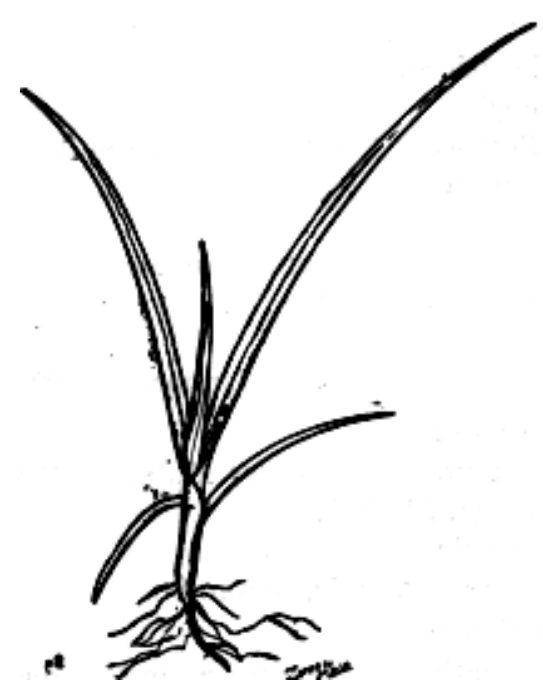

Fig. 6 - Cyperus acicularis (Schrad.) Steud.

Cyperus brevifolius (Rottb.) Hassk. Catal. Hort. bogor: 24, 1844.

Sin. Ccient.:

Kyllinga brevifolia Rottb. Desc. et Icon. 13.

t. 4, 1773.

Kyllinga cruciformes S.R. et S. Syst. Veg. 2.

Mant. 137, 1824.

Kyllinga sororia Kunth. Syst. Veg. 2. Mont. 131, 1834.

Nome vulgar:

capim-de-uma-só-cabeça. 


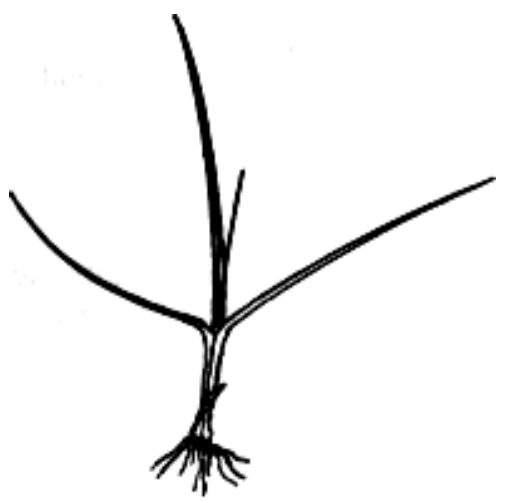

Fig. 7 - Cyperus brevifolius (Rottb.) Hassk.

Etimologia:

devido as suas folhas serem curtas. Ciclo:

anual.

Porte:

herbáceo.

Fenologia:

floresce e frutifica nos meses de novembro a março.

Reprodução:

sementes e vegetativamente através de cur tos rizomas. (Fig. 7).

Cyperus esculentus L. Linnaea 36:290, 1869/70. Sin. Cient.:

Cyperus phymatodes Muhlenb. Descr. uber. Gram. 23, 1817.

Nome vulgar:

tiririca-amarela, manimbu.

Etimologia:

do latim "esculentus, a, um" = que se pode comer.

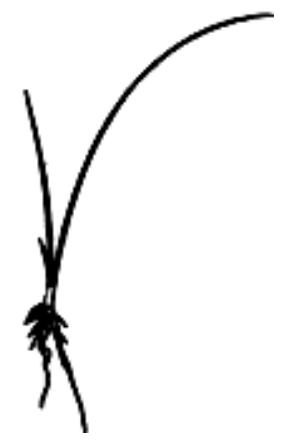

Fig. 8 - Cyperus esculentus L.
Ciclo: perene.

Porte: herbáceo; planta ereta.

Fenologia:

floresce e frutifica nos meses de novembro a março.

Reprodução:

sementes e vegetativamente atravé s de estolões. (Fig. 8).

Cyperus ferax L.C. Rich. Act. Soc. Hist. Nat. Paris 1: 106, 1792.

Sin. Cient.:

Cyperus hanriltoni Kunth. Enum. 2: 90, 1837. Cyperus odoratus Griseb. Brit. West. Isl. 565, 1864.

Nome vulgar: capim-de-cheiro.

Etimologia: do termo latino "ferax" = fértil, possivel mente em alusão ao aspecto vigoroso que a planta apresenta.

Ciclo: anual.

Porte: herbáceo; planta ereta.

Fenologia:

floresce e frutifica nos meses de novembrc a março.

Reprodução:

sementes e vegetativamente através de cur tos rizomas. (Fig. 9).

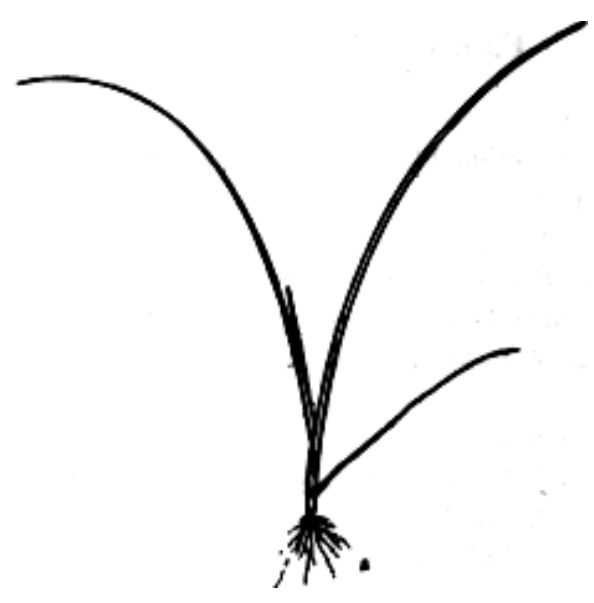

Fig. 9 - Cyperus ferax Rich. 


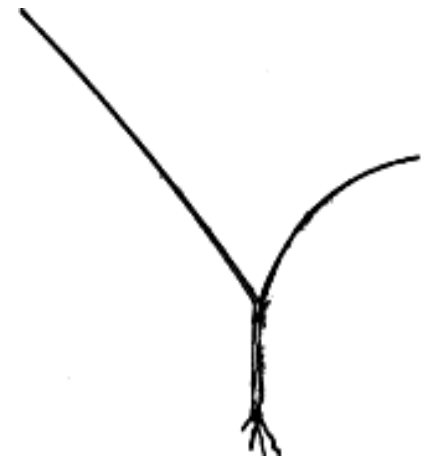

Fig. 10-Cyperus iria L.

Cyperus iria L. Sp. P1. 45, 1753.

Nome vulgar:

$$
\text { tiririca. }
$$

Etimologia:

do latim "iria, ae" = Iria, cidade da Liguria (Itália).

Ciclo: anual.

Porte:

herbáceo; planta ereta.

Fenologia:

floresce e frutifica nos meses de novembro a março.

Reprodução:

sementes mas esporadicamente através de rizomas curtos. (Fig. 10).

Cyperus rotundusL. Sp. P1. ed. 1: 45, 1753.

Sin. Cient.:

Cyperus purpureovariegatus Boeck. Cyp. Nov. 2: 37, 1890.

Chlorocyperus rotundus Palla. Allg. Bot. Zeit. 6: 201, 1900.

Nome vulgar: tiririca, tiririca-verdadeira.

Etimologia:

provêm do latim "rotundus, a, um" = redondo, harmonioso.

Ciclo:

perene.

Porte:

herbáceo; planta ereta.

Fenologia:

floresce e frutifica nos meses de setembro a março.

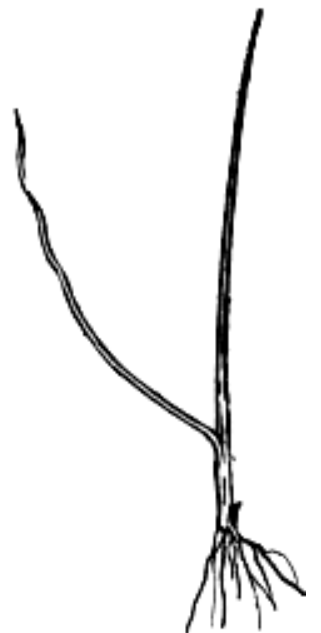

Fig. 11 - Cyperus rotundus L.

Reprodução:

sementes e vegetativamente através de ri zomas. (Fig. 11).

\section{Família Cyperaceae}

Gênero:

Eleocharis R. Br. Prodr. 224, 1810.

Etimologia:

não encontrada.

Eleocharis filiculmis Kunth. Enum. 2: 144, 1837

Sin. Cient.:

Eleocharis rothiana Boeck. Fl. 43: 3, 1860.

Eleocharis balansaiana Boeck. Fl. 63: 159 1879.

Scirpus filiculmis Schrad. ex Griseb. Symb ad. Fl. Arg. 311, 1879.

Nome vulgar:

junco-manso-pequeno.

Etimologia:

devido aos talos muito filamentosos.

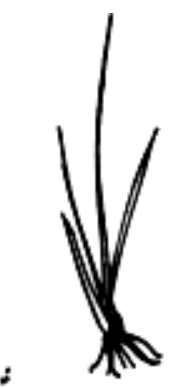

Fig. 12 - Eleocharis filiculmis Kunth. 
Ciclo:

perene.

Porte:

herbáceo; planta ereta.

Fenologia:

floresce e frutifica nos meses de agosto a dezembro.

Reprodução:

sementes e vegetativamente através de rizomas. (Fig. 12).

\section{Familia Gramineae}

Gênero:

Brachiaria (Trin.) Griseb. Ledeb. F1 Ross. 4: 469, 1853.

Etimologia:

Do latim "brachium" = curto, provavelmente em alusão as ramificações que são curtas. Chave para identificação das espécies:

1 - Plúmula de ápice obtuso; bainha das folhas definitivas com esparsos pelos

tarn slúcidos e longos ..............

B. purpurascens.

- Plúmula de ápice agudo; bainha das folhas definitivas com numerosos pelos simples e curtos ........... B. plantaginea.

Brachiaria plantaginea (Link.) Hitch.

Contr. U.S. Nat. Herb. 12: 213, 1909.

Sin. Cient.:

Panicum plantagineum Link. Hort.

Berol. 1: 206, 1827.

Panicum leandri Trin. Gram. Icon. 3: pl. 335, 1835.

Panicum distans Salzm. Doell. Mart. Fl. Bras. 2: 186, 1877.

Nome vulgar: capmi-marmelada, marmelada.

Etimologia:

pela consistência e as pecto tenro de suas folhas.

Ciclo: anual, de mais ou menos 130 dias.

Porte:

herbáceo; planta ereta ou ocasionalmente semi-prostrada.

Fenologia:

floresce e frutifica nos meses de outubro a fevereiro.

Reprodução:

sementes

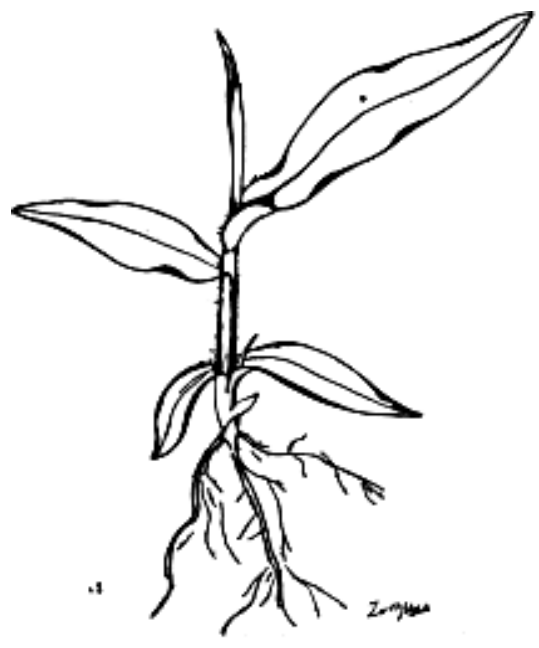

Fig. 13 - Brachiaria plantaginea (Link.) Hitch.

Plântula:

plúmula lanceolada e de ápice agudo. Folha definitiva com bainha brancacenta e curta-mente translúcido-pilosa; lígula membranácea formada por um anel de pelos hialinos; lâmina glabra, estriada, verde na face superior e verdeclara na inferior. Colmo normalmente ereto, cilíndrico e não pigmentado.

Brachiaria purpurascens Henr. Blumea 3: 434, 1940.

Sin. Cient.:

Panicum purpurascens Raddi. Agrost. Bras. 47, 1823.

Panicum barbinode Trin. Acad. Petersb. Mém. 6. Sci. Nat. 1: 256, 1834.

Panicum guadaloupense Steud. Syn. P1. Glum. 1: 61, 1854.

Panicum eguinum Salzm. ex Steud. Syn. Pl. Glum. 1: 61, 1854.

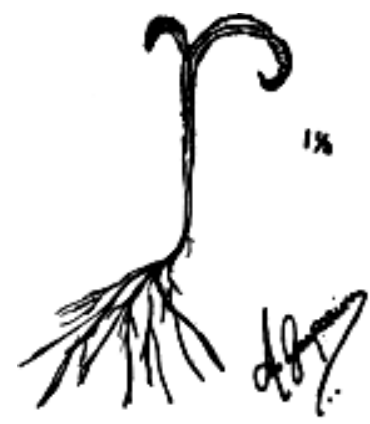

Fig. 14 - Brachiaria purpurascens Henr. 
Panicum pyctigluma Steud. Syn. Pl. Glum. 1:73, 1854.

Brachiaria mutica (Forsk.) Stapf. Prain. Fl. Trop. Afr. 9: 526, 1919.

Nome vulgar:

capim-angola, capim-de-planta, capim-do-para, capim-fino.

Etimologia:

devido à intensa pigmentação antociânica presente nos entre-nós que empresta uma coloração purpúrea às porções das ramificações. - .

Ciclo:

perene.

Porte:

herbáceo; planta estolonífera, ereta ou subprostrada.

Fenologia:

floresce e frutifica nos meses de fevereiro a maio.

Reprodução:

em geral vegetativa através de rizomas, raramente ocorrendo a formação de sementes nas condições do Estado.

Plântula:

plúmula brancacenta, hialina, glabra, de ápice obtuso, fortemente adpressa ao colmo. Folha definitiva com bainha verde-brancacenta, com esparsos pelos simples e hialinos; lâmina verde-clara, estriada, com numerosos pelos simples, longos e translúcidos em ambas as faces e de aspecto muito característico. (Fig. 14).

\section{Familia Graminea e}

Gênero:

Cenchrus L. Sp. Pl. 1049, 1753.

Etimologia:

provavelmente em alusão a forma de sua inflorescência que após frutificar se torna semelhante a uma pequena espiga.

Cenchrus echinatus L. Sp. P1 . 1050, 1753.

Sin. Cient.:

Cenchrus pungens H.B.K. Nov. Gen. et Sp. 1: $115,1815$.

Cenchrus brevisetus Fourn. Mex. Pl. 2: 50, 1886.

Cenchrus echinatus brevisetus Scribn Millsp. Field. Mus. Bot. 2: 26, 1900

Nome vulgar:

capim-carrapicho, carrapicho.

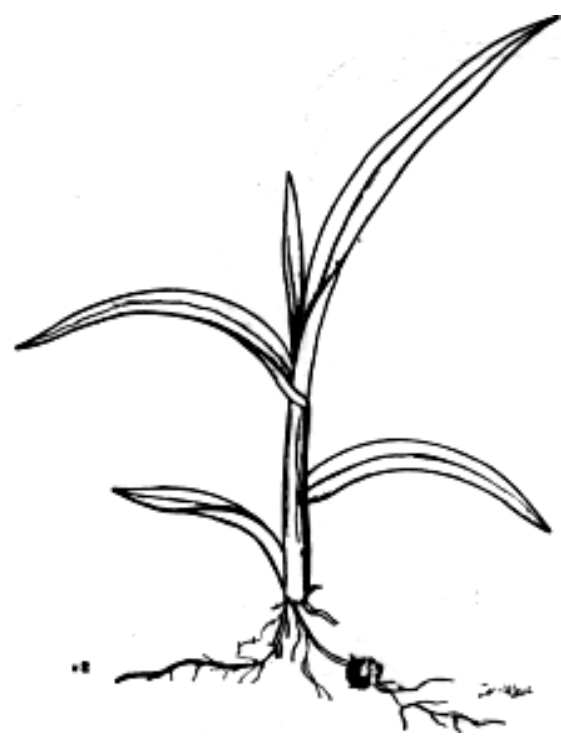

Fig. 15 - Cenchrus echinatus $L$.

\section{Etimologia:}

devido as aristas rígidas como espinhos.

Ciclo: anual.

Porte:

herbáceo; eventualmente planta subpros trada.

Fenologia:

floresce e frutifica intensamente nos meses mais quentes, embora ocorra o ano todo.

Reprodução:

sementes.

Plântula:

plúmula densamente pigmentada de anto cianina. Folha definitiva com bainha glabra, ciliada no ápice e densamente pigmentada de antocianina; lígula com um anel de pelos translúcidos; lâmina lanceolada, glabra, membranácea, verde-brilhante e estriada. $\mathrm{Na}$ fase jovem, arrancand o-se cuidadosamente a plântula nota-se, em suas raízes, a presença de infrutescência como mostra a estampa. (Fig. 15).

\section{Familia Gramineae}

Gênero:

Cynodon (L.) Rich. Pers. Syn. P1. 1: 85, 1805.

Etimologia:

em alusão a sua presença na cidade de Ló crida, na Etólia, no golfo de Corintho. 


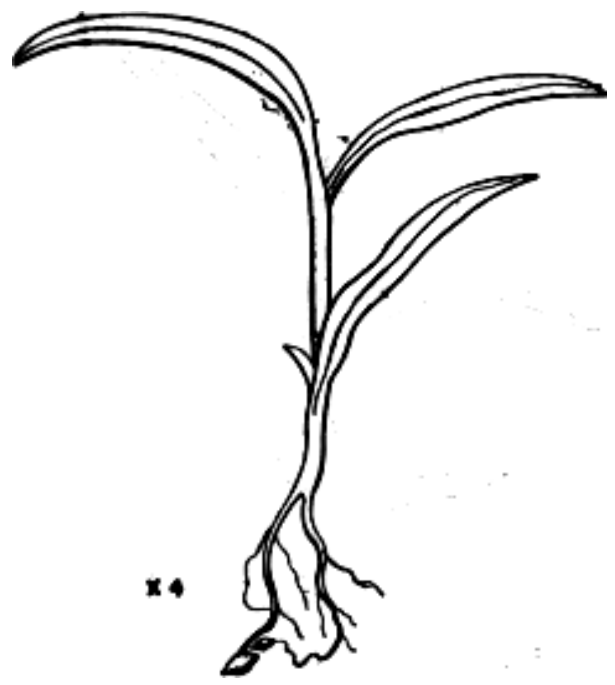

Fig. 16 - Cynodon dactylon (L.) Pers.

Cynodon dactylon (L.)Pers. Syn. Pl. 1: 85, 1805. Sin. Cient.:

Paniaum dactylonL. Sp. P1. 58, 1753. Capriola dactylon Kuntze. Rev. Gen. P1. 764, 1891.

Nome vulgar:

capim-de-burro, grama-seda, capim-de-bermuda.

Etimologia:

por apresentar sua inflorescência em racemos distribuídos à semelhança de pés como os dedos das aves.

Ciclo:

perene.

Porte:

herbáceo; planta rasteira.

Fenologia:

floresce e frutifica intensamente nos meses de novembro a março.

Reprodcção:

através de rizomas escamosos e estolões, sendo a reprodução por sementes mais rara, dificilmente ocorrendo em condições de campo.

Plântula:

plúmula curto-lanceolada, brancacenta, estriada e glabra; lígula membranácea e hialina; lâmina lanceolada de ápice obtuso ou agudo, estriada. (Fig. 16).

\section{Familia Gramineae}

Gênero:

Digitaria Heister. Scop. Fl. Carn. 2. 1: 52, 1772.

Etimologia:

por apresentar as inflorescências com racemos digitados.

Chave para identificação das espécies:

é muito dificil separar essas duas espécies no estádio de plântula, o caráter que pode ser observado e incorrer-se no menor número de erro é a constante pigmentação antociânica apresentada pela $D$. sanguinalis.

Digitaria horizontalis Willd. Enum. P1. 92, 1809.

Sin. Cient.:

Milium digitatum Swartz. Prodr. Veg.

Ind. Occ. 24, 1789.

Agrostis digitada Poir. Lam. Encycl. Sup. 1: $258,1810$.

Axonopus digitatus Beauv. Ess. Agrost. 12: $154,1812$.

Panicum horizontalis G. Meyer. Prim. Fl. Essq. 54, 1818.

Digitaria jamaicensis Spreg. Syst. Veg. 1: $272,1825$.

Digitaria setosa Desv. ex Hamilt. Prodr. P1. Ind. Occ. 6, 1825.

Paspalum digitatum Kun th. Rev. Gram. 1: 24, 1829.

Digitaria sanguinalis var. horizontalis Rendle Cat. Afr. Pl. Welw. 2: 163, 1899.

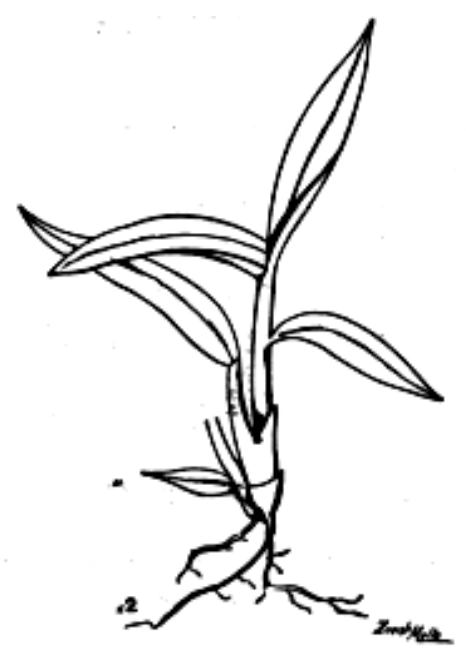

Fig. 17 - Digitaria horizontalis Willd. 
Panicum sanguinale var. digitatum Hack. ex Urban. Symb. Ant. 5: 86, 1903.

Panicum sanguinale subesp. horizontale Hack. Ergeb. Bot. Exped. Akad. Wiss. Math. Naturw. 79: 69, 1908.

Nome vulgar: capim-colchão, capim-colchão-miúdo.

Etimologia: pelo desenvolvimento prostrado que a planta apresenta.

Ciclo: anual.

Porte:

herbáceo; planta ereta ou prostrada.

Fenologia:

florescimento de setembro a março.

Reprodução:

sementes e através de enraizamento caulinar.

Plântula:

plúmula lanceolada, de ápice acuminado, curto-pilosa em ambas as faces, estriada. Folha definitiva com bainha nitidamente estriada, enverdeada, densamente curto-pilosa, raramente pigmentada de antocianina; lâmina lanceolada, curto-pilosa em ambas as faces, estriada e eventualmente com pigmentação antociânica na face ventral. (Fig. 17).

\section{Familia Graminea e}

\section{Gênero:}

Echinochloa Beauv. Ess. Agrost. 53, pl. 11. fl. 2, 1812 .

Etimologia:

provêm do grego, "echinos"

ouriço,

"chloa" = grama.

Chave para identificação das espécies:

1 - Bainha das folhas definitivas reluzentes e longas E. crus-pavonis

2 - Bainha das folhas definitivas opacas e curtas E. colonum.

Digitaria sanguinalis (L.) Scop. Fl. Carn. ed. 2. 1: $52,1772$.

Sin. Cient.:

Panicum sanguinale L. Sp. Pl. 57, 1753.

Dactylon sanguinalis Vil. Hist. P1. Dauph. 2: 69, 1787.

Paspalum sanguinalis Lam. Tabl. Ecycl. 1: 176, 1791.

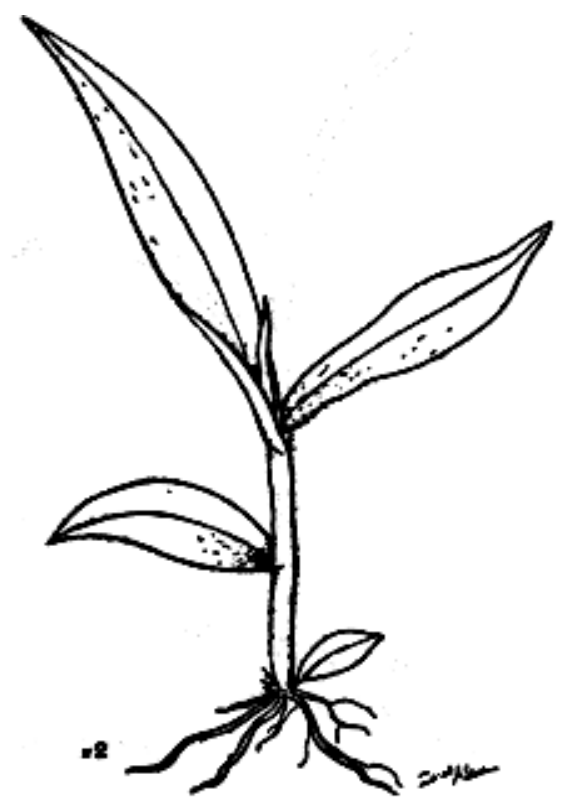

Fig. 18 - Digitaria sanguinalis (L.) Scop.

Digitaria praecox Willd. Enum. Pl. 91, 1809. Digitaria marginata Link. Enum. Pl. 1: 102, 1821.

Digitaria fim briata Link. Hort. Berd. 1: 226, 1827.

Digitaria adscendens Henr. Blumeá -1: 94, 1934.

Nome vulgar:

capim-colchão, capim-de-colchão.

Etimologia:

devido a grande pigmentação antociânica presente nas folhas.

Ciclo: anual.

Porte:

herbáceo; planta ereta ou subprostrada, neste caso emitindo raízes nos nós em contacto com o solo.

Fenologia:

floresce e frutifica nos meses de setembro a marco.

Reprodução: sementes e através de enraizamento caulinar.

Plântula:

plúmula verde-clara e com nítida pilosidade translúcida. Folha definitiva com lígula curta, membranácea e translúcida, oval-lanceolada, verde-clara em ambas as faces, curto- 


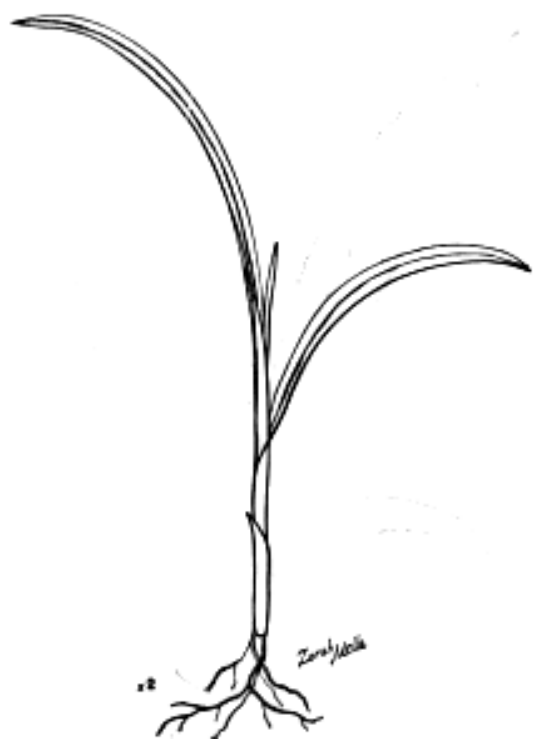

Fig. 19 - Echinochloa colonum (L.) Link.

pilosa, levemente enrolada no ápice (Fig. 18).

Echinochloa colonum (L.) Link. Hort. Berol. 2: 209, 1833.

Sin. Cient.:

Panicum colonum L. Syst. Nat. ed. 10. 2: 870, 1759.

Milium colonum Moench. Meth. P1. 202, 1794. Oplismenus colonus H.B.K. Nov. Gen. et Sp. 1: 108, 1816.

Panicum zonale Guss. Fl. Sic. Prodr. 1: 62, 1827.

Panicum incertum (Bosc.) Steud. Nom. Bot. ed. 2: 258, 1841.

Panicum colonum zonate L.H. Dewy. Contrib. U.S. Nat. Herb. 2: 502, 1844.

Panicum prorepens Steud. Syn. Pl. Glum. 1: 46, 1854.

Echinochloa colonum zonalis Woot. et Standl. N. Mex. Coll. Agr. Bull. 81: 45, 1912. Nome vulgar:

capim-arroz, capituva, capim-jaú, capim-dacolônia.

Etimologia: por ocorrer no campo cultivado pelo homem. Ciclo: anual com mais ou menos 120 dias. Porte: herbáceo; planta ereta.
Fenologia:

floresce e frutifica nos meses de setembro a março.

Reprodução:

sementes.

Plântula:

plúmula verde-brancacenta, glabra e curta. Folha definitiva com bainha glabra, verdeclara e reluzente; lâmina glabra, verde-clara, aguda e estriada. Geralmente toda a porção basal da plântula apresenta pigmenta cão antociânica. (Fig. 19).

Echinochloa crus-pavonis (H.B.K.) Schult. Mantissa 2: 269, 1824.

Sin. Cient.:

Oplismenus crus-pavonis H.B.K. Nov. Gen. et Spec. 1: 108, 1815.

Panicum crusgalli var. sabulicolum Trin. Gram. Icon. 2: pl. 163, 1828.

Panicum sabulicola Ness. Agrost. Bras. 258, 1829.

Panicum crus-pavonis Ness. Agrost. Bras. 259, 1829.

Echinochloa crusgalli. crus-pavonis Hitch. U.S. Nat. Herb. Contr. 22: 148, 1920.

Nome vulgar:

capituva, capim-jaú, capim-da-colônia, capim-arroz.

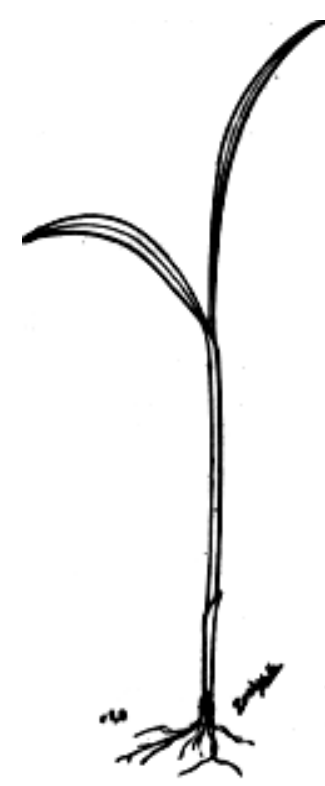

Fig. $20-$ Echinochloa crus-pavonis (H.B.K.) Schult. 


\section{Etimologia:}

Do latim "crus, uris" = pata, pé, perna e Ciclo: "pavonis" = pavão.

anual com mais ou menos 120 dias.

Porte:

herbáceo; planta ereta.

Fenologia:

floresce e frutifica nos meses de outubro a marco.

Reprodução: sementes.

Plântula:

plúmula verde-brancacenta, glabra e curta. Folha definitiva com bainha mais longa que a das outras espécies do gênero, glabra, verdeclara e reluzente; lâmina de ápice agudo, verde-clara, estriada e glabra. (Fig. 20).

\section{Familia Gramineae}

\section{Gênero:}

Eleusine Gaertn. Frut. et Sem. 1: 7. pl: 1. f. 11,1788 .

Etimologia:

cidade da Ática, perto do Golfo Savonico, próximo ao Rio Cephiso, célebre pelos mistérios de Eleusis, hoje Lyssina, na Grécia onde se cultuou Ceres, a deusa da colheita.

Eleusine indica (L.) Gaertn. Fruct. et Sem. 1: 8, 1788.

Sin. Cient:

Cynosurus indicus L. Sp. P1. 72, 1753.

Eleusine gracilis Salisb. Prodr. Stirp. 19, 1796.

Eleusine domingensis Sieber ex Schult. Mantissa $2: 323,1824$

Cynodon indicus Raspail. Ann. Sci. Nat. Bot. 5: 303, 1825.

Chloris repens Steud. Nom. Bot. ed. 2: 353, 1825.

Eleusine scabra Fourn. ex Hemol. Biol. Centr. Am. Bot. 3: 65, 1885.

Eleusine indica var. major Fourn. Mex. Pl. 2: $145,1886$.

Nome vulgar:

capim-pé-de-galinha. pé-de-galinha.

Etimologia:

Ciclo:

procedente da região das índias.

anual com mais ou menos 120 dias.

Porte:

herbáceo; planta ereta, muito raramente semi-prostrada.
Fenologia:

floresce e frutifica nos meses de setembro a janeiro.

Reprodução:

sementes.

Plântula:

plúmula glabra, lanceolada, de ápice agudo, verde-escura e estriada. Folha definitiva com bainha caracteristicamente comprimida, glabra, verde-clara e estriada; lâmina lanceolada, glabra e estriada; colar brancacento. O colmo compresso, as estrias da bainha e da lâmina foliar, caracterizam prontamente esta espécie. (Fig. 21).

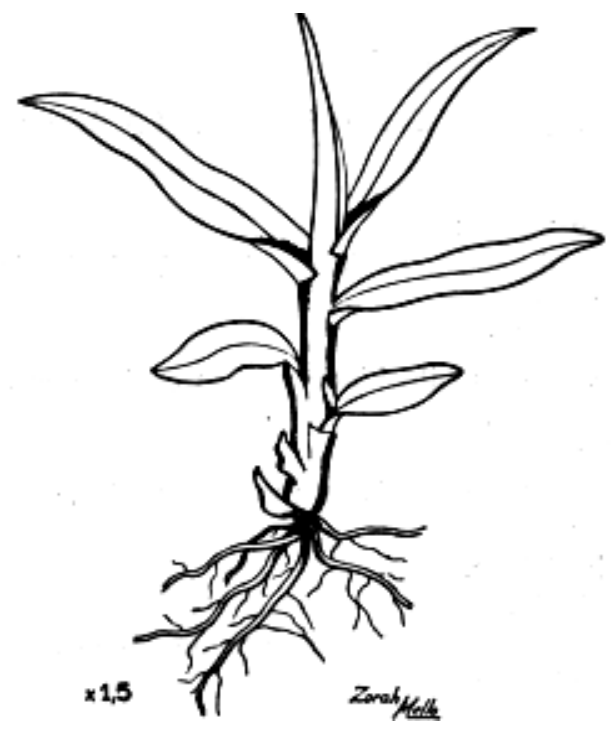

Fig. 21 - Eleusine indica (L.) Gaertn.

\section{Família Graminea e}

Gênero:

Eragrostis Host. Icon. Gram. Aus tr. 4: 14, pl. 24,1809 .

Etimologia:

do grego, "er" = primavera e "agrostis" = grama.

Eragrostis pilosa (L.) Beauv. Ess. Agrost. 71: 162, 1812

Sin. Cient.

Poa pilosa L. Sp. Pl. 68, 1753.

Poa eragrostis Watt. Fl. Carol. 80, 1788.

Eragrostis filiformis Link. Hort. Berol. 1: 191, 1827.

Poa linkii Kunth. Rev. Gram. 1: 113, 1829. 


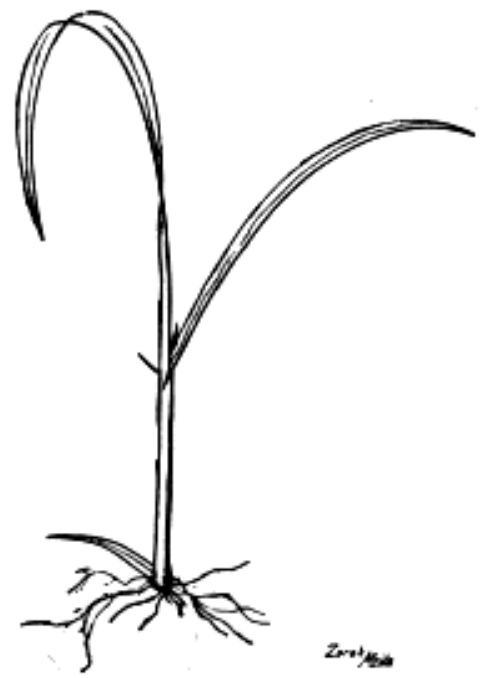

Fig. 22 - Eragostis pilosa (L.) Beauv.

\section{Nome vulgar:}

capim-barbicha-de-alemão, barbicha-de-alemão.

Etimologia:

devido a pilosidade que as espiguetas apresentam.

Ciclo:

anual com mais ou menos 120 dias.

Porte:

herbáceo.

Fenologia:

floresce abundantemente de janeiro-março.

Reprodução: sementes.

Plântula:

plúmula glabra e estriada. Folha definitiva com bainha nitidamente estriada, glabra; lígula membranácea, com pelos simples, translúcidos e bem desenvolvidos; lâmina glabra, lanceolada e estriada. (Fig. 22).

\section{Familia Gramineae}

Gênero:

Ischaemum L. Sp. Pl. 1049, 1753.

Etimologia:

em latim, "ischaemon, $\mathrm{i}$ " = certa planta desconhecida

Ischaemum rugosum Salisb. Icon. Stirp. Rar. 1. pl. 1, 1791.

Nome vulgar:

capim-macho.
Etimologia:

por apresentar suas cariopses totalmente enrugadas.

Ciclo:

anual com mais ou menos 120 dias.

Porte:

herbáceo; planta ereta.

Fenologia:

floresce e frutifica predominantemente nos meses de outubro-março.

Reprodução:

sementes.

\section{Plântula:}

plúmula curta, fortemente adpressa ao caule, aguda, brancacenta, glabra e com base pigmentada de antocianina; lígula membranácea e brancacenta; lâmina foliar lanceolada, de ápice agudo, verde-clara e glabra. (Fig. 23).

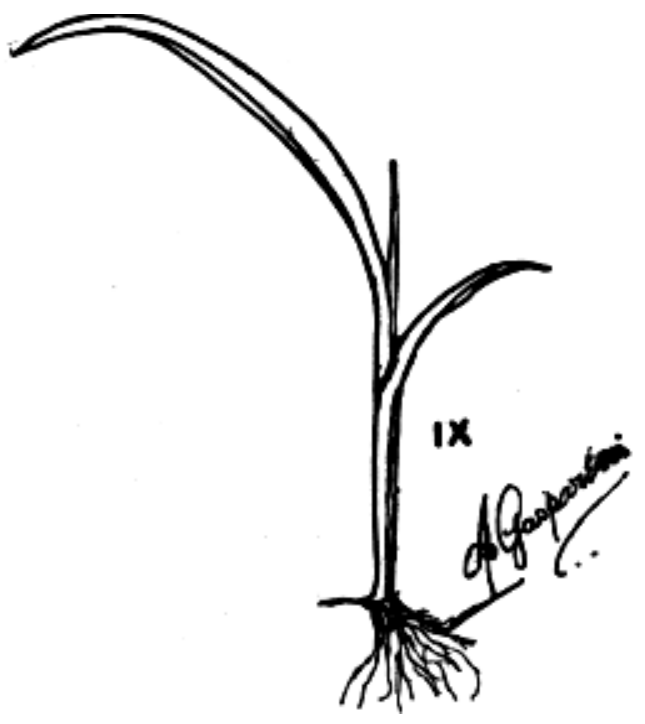

Fig. 23 - Ischaemum rugosum Salisb.

\section{Família Gramineae}

\section{Gênero:}

Paspalum L. Syst. Nat. ed. 10. 2: 855, 1759.

Etimologia:

provêm do hábito de crescimento da planta que normalmente constitui pastos.

Paspalum acuminatum Raddi Agrost. Bras. 25, 1823.

Nome vulgar: grama-doce. 
Etimologia:

em alusão a forma acuminada de suas espiguetas.

Ciclo:

$$
\text { anual. }
$$

Porte:

herbáceo; planta prostrada.

Fenologia:

floresce e frutifica nos meses de setembro-janeiro.

Reprodução:

sementes e através de colmos enraizados.

Plântula:

plúmula brancacenta, glabra, levemente estriada e de ápice agudo. Folha definitiva com bainha brancacenta, estriada com pelos simples e alvo-translúcidos; ligula curta, membranácea e hialina; lâmina lanceolada, de ápice acuminado, verde, estriada e com esparsos pelos simples e hialinos na face superior. (Fig. 24).

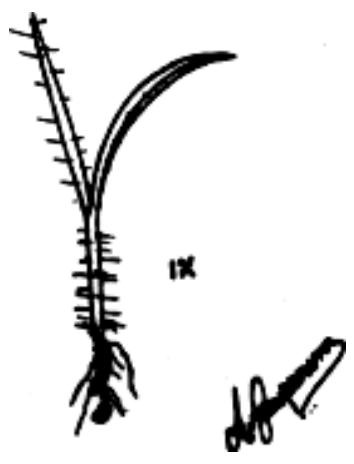

Fig. 24 - Paspalum acuminatum Raddi

Família Juncaceae

Gênero:

Juncus L. Syst. ed. I, 1735.

Etimologia:

do latim "juncus, i" = junco, nome de homem que ocupava posição no consulado do segundo século da era cristã.

Juncus effusus L. Sp. P1. 326, 1735.

Sin. Cient.:

Juncus aemulans Liebm. in Kjoeb. Vidensk. Meddel. 38, 1850.

Juncus diff usus Hoppe in Flora I. 186,

1819. Nome vulgar: junco, junquinho.

Etimologia: em alusão a sua característica vegetativa,

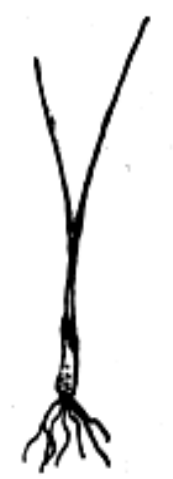

Fig. 25 - Juncus effusus L.

pois a planta apresenta-se pendente para um lado.

Ciclo:

anual.

Porte:

herbáceo; planta ereta, sem ramificações.

Fenologia:

floresce e frutifica intensamente nos meses mais frios do ano. Normalmente entre maio-julho.

Reprodução:

exclusivamente por sementes.

Plântula:

plúmula insignificante, hialina e glabra. Primeiras folhas definitivas muito tênues, sub-articuladas, glabras em ambas as faces e de coloração verde-clara. (Fig. 25).

\section{Familia Pontederiaceae}

\section{Gênero:}

Eichornia Kunth. Enum. Plant. 4: 129, 1843.

Etimologia:

em homenagem à J. A. Eichhorn, um ministro prussiano, nascido em 1779.

Eichornia crassipes (Mart.) Solms - Lauback Mon. Pont. 527, 1883.

Sin. Cient.:

Ponte deria crassipes Mart. Nov. Gen. et Sp. PI. 1: 9, 1824.

Pontederia azurea Hook. Bot. Mag. 2932, 1829.

Eichornia speciosa Kunth. Enum. Plant. 4: 131, 1843.

Nome vulgar:

aguapé. 


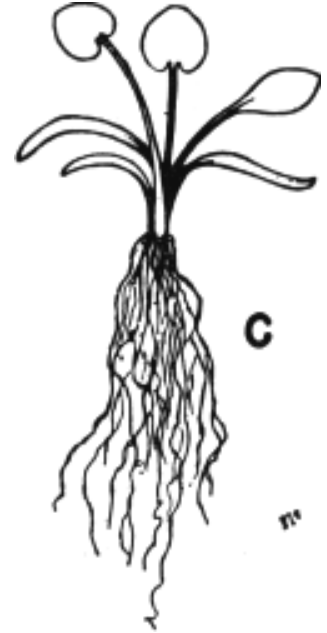

Fig. 26 - Eichornia crassipes (Mart.) Solms Lauback.

Etimologia: Ciclo:

devido as suas folhas grossas, espessas. anual

Porte: herbáceo.

Fenologia:

floresce nos meses de outubro a janeiro e

frutifica de dezembro a março.

Reprodução:

sementes e multiplicação vegetativamente por estolhos.

Plântula:

folhas rosulado-basilares, sendo a cotiledonar, lanceolada, de ápice agudo, glabra, verde-clara, esponjosa e carnosa. Primeiras folhas definitivas longo-pecioladas, glabras, carnosas e verde-claras, lâmina foliar alargada, de ápice arredondado, base reta ou Ieve cordada e de bordos íntegros. (Fig. 26).

O levantamento e identificação das plantas invasoras da cultura de arroz mostrou 6 famílias de monocotiledôneas sendo que, as mais representativas, quantitativamente, são Gram ineae, Cyperaceae e Commelinaceae.

Todas as espécies apresentaram hábito de crescimento herbáceo.

A reprodução foi quase que exclusivamente por sementes, sendo que nas espécies Commelina nudiflora, Brachiaria purpurascens e Cynodon dactylon observou-se reprodução vegetativa.
Com exceção das espécies : Sagittaria montevidensis, Commelina nudiflora, Cyperus esculentus, Cyperus rotundus; Brachiaria purpurascens, Cynodon dactylon e Eleocharis filiculmis, que são perenes, as demais são anuais.

Das espécies tratadas, apenas Juncus effusus apresentou florescimento intenso nos mes es mais frios do ano, enquan to que Eleocharis filiculmis iniciou seu florescimento no final do inverno.

\section{LITERATURA CITADA}

1. Aranha, Ci Bacchi, O \& Letiāo F: H. F. Plantas Invasoras de Culturas no Estado de Sâo Pauto. vol. III (em publicação).

2. Crovetto, R. M. \& Piccinini, B. G. Bibliogra. fia Argentina sobre malezas. Publicacion Técnica n. 17, Ministério da Agricultura. 91p., 1948.

3. Crovetto, R. M. las matezas de los montes frutales en el nordeste de Entre Rios. Pu. blicación Técnica n.. $54,44 \mathrm{p} ., 1950$.

4. Crovetto, R. M. Las malezas de los cespedes la capital federal y alrededores. $\mathrm{Pu}$ blicación Técnica n. 41, 46p. 1950.

5. Freire, C. V. Chaves Analiticas. Dist. Liv. Kosmos, 366p., 1943.

6. Font Quer, P.. Diccionario de Botânica. Edit. Labor S/A, 1244p., 1953.

7. Gemtchujnicov, I.. Chave artificial para a identificação de plantas daninhas do Estado de Säo Paulo. Apostila mimeografa. da. F. C. M. B. B., 266p., 1968.

8. Hitchcock, A. S.. The North American Species of Echinochloa, Contribution from the United States Nacional Herbarium 22(3): $133 \cdot 154,1920$.

9. Hitchcock, A. S. Grasses of Britsh Guiana. 22 (6) : $439-514,1922$.

10. Hitchcock, A. S. A text-book of grasses. The Macmillan Company 276p., 1922.

11. Isely, D.. Weed identification and control. Iowa State University Press. Amer., Iowa U.S.A., 400p. 1962.

12. Kuhlmann, J. G.. Declinaçōes dos substantivos latinos ou gregos alatinados mais usados em botânica e sua significação em portuguess. Biblioteca Cientifica Brasileira. Série A-III. Instituto Nacional do Livro. Rio de Janeiro, 43p. 1954.

13. Lagos; J. A. \& Calles, F. Malas hierbas en cafetales de El Salvador. Facultad de Cienc. Agron., Bol n. 2, 36p., 1968. 
14. Leitão F. ${ }^{\circ}$ H. F. \& Aranha, C.. Noções sobre sistemática de plantas invasoras. Apostila Escola Superior de Agriccultura "Luiz de Queiroz", 44p., 1970.

15. Leitão F: H, F.; Aranha, C. \& Bacchi, O. Plantas Invasoras de Culturas no Estado de São Paulo. HUCITEC, São Paulo, vol. I, 291p., 1972.

16. Leitão F.; H. F.; Aranha, C. \& Bacchi, O.. Plantas Invasoras de Culturas no Estado de Soã Paulo. HUCITEC, São Paulo, vol. II, 597p., 1975.

17. Marinis, G. et alii.. Texto básico de controle químico de plantas daninhas. Piracicaba. 257p., 1969.

18. Rocha, T. R.; Souza, D. M.; Leitāo F. H.
F.; Aranha, C. \& Santos, C. A. L.. Herbicidas em arroz - I. Campinas. Instituto Agronômico, 1977. 12p. (Circular n. 73).

19. Saraiva, F. R. do Santos. Novíssimo diccionário latino-portuguez etymologico, prosolico, histórico, geographico, mythologico, biographico, etc. 2.: ed., Rio de Janeiro, $1297 \mathrm{p}$.

20. Souza, D. M.; Leitão F.* H. F.; Aranha, C. \& Santos, C. A. L. Herbicidas em arroz - II. Campinas. Instituto Agronômico, 1977. 11p. (Circular n." 75).

21. Souza, D. M.: Leitão F o: H. F.; Aranha, C. \& Santos, C. A. L. Herbicidas em arroz - III. Campinas. Instituto Agronômico, 1977. 11p. (Circular n." 76). 